\title{
ALGUMAS REFLEXÕES SOBRE A HISTÓRIA DA MATEMÁTICA E AS CONTRIBUIÇÕES DA TORRE DE HANÓI NA APRENDIZAGEM DE FUNÇÃO EXPONENCIAL
}

\section{SOME REFLECTIONS ON THE HISTORY OF MATHEMATICS AND THE CONTRIBUTIONS OF THE HANOI TOWER IN LEARNING THE EXPONENTIAL FUNCTION}

\author{
Raul Gomes Antunes ${ }^{1}$ \\ Instituto Federal de Educação, Ciência e Tecnologia da Bahia \\ Lucas Ruan dos Santos Cardoso ${ }^{2}$ \\ Instituto Federal de Educação, Ciência e Tecnologia da Bahia \\ João Batista Rodrigues da Silva ${ }^{3}$ \\ Instituto Federal de Educação, Ciência e Tecnologia da Bahia
}

\begin{abstract}
Resumo
Este estudo, na modalidade de relato de experiência, tem como objetivo abordar alguns aspectos históricos da Torre de Hanói visando introduzir a lei de formação da função exponencial. Por meio de uma abordagem qualitativa, buscou-se apresentar de forma subjetiva, o entendimento dos estudantes referente à função exponencial, mediada pela história que apresenta as regras utilizadas na Torre de Hanói. Para tanto, o Grupo de Pesquisa em Ensino de Ciências Naturais e Matemática, após realizar algumas reflexões sobre o processo de ensino e aprendizagem no IFBA, campus Juazeiro, percebeu a necessidade de realizar atividades que envolvessem o ensino de matemática. Assim, após o planejamento da oficina, percebeu-se a necessidade de desenvolvê-la em vários momentos. O primeiro momento proporcionou o engajamento dos estudantes. No segundo momento, foram apresentadas algumas histórias do surgimento do jogo, seguida de uma atividade para recapitular as discussões. No terceiro momento, os participantes foram desafiados a refletir sobre a relação entre as peças da Torre de Hanói com a quantidade de movimentos, a partir das regras abordadas na história. No quarto momento, por meio de uma dinâmica, foi discutida a relação das grandezas e funções, usando os pés e calçados dos participantes. No quinto momento, foi entregue uma atividade com questões acerca de função exponencial e a Torre de Hanói. E, no último momento, houve uma competição com a Torre de Hanói entre os participantes. Todos os momentos da oficina foram interativos, dinâmicos e mobilizaram os conhecimentos matemáticos acerca da função exponencial e da Torre de Hanói. As discussões convergiram para estabelecer a importância da História da Matemática e do material manipulativo para a aprendizagem
\end{abstract}

$\frac{1}{2} \frac{\text { raulg.antunes@gmail.com }}{\text { lruan241175@gmail.com }}$
joaosilva@ifba.edu.br DOI: $10.30938 /$ bocehm.v7i20.2791 
Algumas reflexões sobre a História da Matemática e as contribuições da Torre de Hanói na aprendizagem de função exponencial

Raul Gomes Antunes, Lucas Ruan dos Santos Cardoso e João Batista Rodrigues da Silva

da função exponencial, mediada por uma sequência didática em que ficou perceptível o significado de cada elemento na construção do conhecimento.

Palavras-chave: História; Torre de Hanói; Função Exponencial; Aprendizagem; Interação.

\begin{abstract}
This study, in the form of an experience report, aims to address some historical aspects of the Tower of Hanoi in order to introduce the law of formation of the exponential function. Through a qualitative approach, we sought to present, in a subjective way, students' understanding of the exponential function, mediated by the history that presents the rules used in the Tower of Hanoi. To this end, the Research Group on Teaching Natural Sciences and Mathematics, after carrying out some reflections on the teaching and learning process at the IFBA, Juazeiro campus, realized the need to carry out activities involving the teaching of mathematics. Thus, after planning the workshop, there was a need to develop it at various times. The first moment provided the students' engagement. In the second moment, some stories about the emergence of the game were presented, followed by an activity to recap the discussions. In the third moment, the participants were challenged to reflect on the relationship between the pieces of the Tower of Hanoi and the amount of movements, based on the rules covered in the story. In the fourth moment, by means of a dynamic, the relationship of magnitudes and functions was discussed, using the feet and shoes of the participants. In the fifth moment, an activity was delivered with questions about exponential function and the Tower of Hanoi. And, at the last moment, there was a competition with the Tower of Hanoi among the participants. All moments of the workshop were interactive, dynamic and mobilized mathematical knowledge about the exponential function and the Tower of Hanoi. The discussions converged to establish the importance of the History of Mathematics and of the manipulative material for the learning of the exponential function, mediated by a didactic sequence in which the meaning of each element in the construction of knowledge was noticeable.
\end{abstract}

Keywords: History; Hanoi Tower; Exponential function; Learning; Interaction.

\title{
Introdução
}

Numa sociedade mutável, em que surgem a cada instante inovações de várias naturezas, reinventar o processo de ensinar é uma necessidade. Pois o professor é desafiado a refletir sobre sua prática e apresentar possibilidades que insiram os alunos na rota da aprendizagem.

$\mathrm{Na}$ dinâmica de ensinar e aprender os conteúdos matemáticos percebe-se algumas dificuldades nesse processo. Nesta ação, espera-se que o professor busque meios que contribuam com a aprendizagem desses conteúdos. Com essa preocupação, a Educação Matemática tem possibilitado, por meio de estudos, algumas metodologias de ensino que colaboram com a construção do conhecimento, tais como: Tecnologia na Educação 
Algumas reflexões sobre a História da Matemática e as contribuições da Torre de Hanói na aprendizagem de função exponencial

Raul Gomes Antunes, Lucas Ruan dos Santos Cardoso e João Batista Rodrigues da Silva

Matemática, Etnomatemática, Modelagem, História da Matemática, Jogos e materiais manipulativos, dentre outras. Elas podem colaborar com o ensino e aprendizagem com mais significado.

Recorrer a essas metodologias de ensino contribui com uma tomada de decisão sobre o caminho que pretende seguir, a fim de que o estudante aprenda o conteúdo matemático. É nessa tomada de decisão que se optou pelo uso da História da Matemática na construção do conteúdo função exponencial.

Historicamente, a Torre de Hanói em sua concepção vem sendo composta de estratégias que repercutem na mobilização de conceitos matemáticos. Para Breda; Hummes; Lima (2013) o uso do instrumento Torre de Hanói vem com regras embutidas que corroboram com o conhecimento acerca da função exponencial por meio das regras e da história.

Para Lima (2013) a história trazida pela lenda da Torre de Hanói resultou num jogo educativo que colaborou com a mobilização de um conhecimento matemático devido as suas estratégias.

Assim a junção entre a História da Matemática e os materiais manipulativos podem contribuir com a aprendizagem de conteúdos matemáticos.

\section{A importância do uso da História da Matemática como recurso metodológico}

No espaço escolar, talvez, apenas a exposição do conteúdo não seja a forma mais adequada que possa despertar o processo de aprendizagem dos estudantes, entretanto, refletir sobre essa prática e possibilitar meios de aprender é o essencial. Por isso, Costa (2016) indica que a apropriação da História da Matemática é uma estratégia eficiente, pois a matemática está presente na história das civilizações. Logo, ao se ater a essas histórias, como, por exemplo, a história do surgimento da Torre de Hanói, um conteúdo matemático que o envolve, no caso, função exponencial, pode se tornar mais compreensível aos estudantes. Essa relação com a História da Matemática por meio do professor pode contribuir com uma prática mais adequada que conduza os alunos a perceber o verdadeiro significado da matemática para a vida das pessoas.

Por isso, Costa (2016) reafirma que ao usar a História da Matemática no processo de ensino contribui também com a desmistificação de que há seletas pessoas que conseguem compreender a Matemática. Assim, 


\begin{abstract}
O uso dos fatos históricos na sala de aula proporciona um melhor entendimento dos alunos no que diz respeito à dimensão histórica dos assuntos envolvidos, despertando assim o interesse dos alunos, motivando-os ainda mais a buscar o conhecimento. O professor precisa despertar nos alunos o aspecto investigativo para que ele próprio busque alternativas para resolver problemas, propiciando assim que os alunos desenvolvam o senso crítico, colaborando para que, se forme cidadãos mais críticos e conscientes do seu papel na sociedade contemporânea, o que faz com que se tenha uma possibilidade mais evidente de êxito na construção do conhecimento. Oliveira, Oliveira_e Vaz (2014, p. 460)
\end{abstract}

Imbuído do mesmo pensamento, Costa (2016) menciona que o uso da História da Matemática como metodologia de ensino pode contribuir para que aumente o interesse dos estudantes pela matemática.

É salutar destacar que existe estudo, como o de Dias; Saito (2009), acerca das propostas e tendência do uso História da Matemática, o qual mostra que há três aspectos importantes ao integrar História e Matemática. O primeiro, diz respeito a História que permitiu uma outra visão da Matemática, destaca como uma atividade intelectual e humanizadora e não somente como um conjunto de técnicas. O segundo, mostra a importância da integração entre a História e a Matemática contribuindo com outra percepção da matemática, dando enfoque do que são os objetos matemáticos a partir do contexto histórico. O terceiro, trata-se da relação entre a matemática e outras disciplinas ao abordar o desenvolvimento do conceito matemático, destacando o aspecto interdisciplinar, visto que a história possibilita a relação com outras áreas do conhecimento.

Então, não se pode perder de vista que a matemática presente na sala de aula é produto de ações da humanidade que ao longo da história começou a desenvolver técnicas e estratégias para resolver alguns problemas que a envolve, conforme apresentou Lara (2013). Pesquisadores da Educação Matemática não tem medido esforços para dar significado ao ensino dos conteúdos matemáticos, colaborando com a ruptura do desinteresse dos alunos pela matemática, como menciona Lara (2013, p. 52):

[...] é comum o professor ouvir questionamentos sobre "quem inventou tal conceito", "quando tal conceito foi criado" ou "o que aquela pessoa estava pensando no momento em que criou tal conceito". As respostas a perguntas desse tipo, quando bem abordadas, podem tornar-se um modo de tratar a Matemática de uma maneira mais atrativa, interessante e desafiante, além de contribuir para a aprendizagem do estudante. 
Algumas reflexões sobre a História da Matemática e as contribuições da Torre de Hanói na aprendizagem de função exponencial

Raul Gomes Antunes, Lucas Ruan dos Santos Cardoso e João Batista Rodrigues da Silva

Questionamentos dessa natureza nos ajudam a refletir e a ter convicção de que a história da matemática não pode estar ausente do processo de ensino e aprendizagem dos conteúdos matemáticos.

\section{O uso de jogos e materiais manipulativos atrelados à história nas aulas de matemática}

Olhando para a realidade dos alunos que estão na escola, sobretudo suas lacunas e evolução na aprendizagem, além das motivações na busca de ultrapassar as barreiras do desconhecimento é que o professor precisa firmar a sua prática. É pensando nisso que as estratégias de ensino bem definidas podem provocar aprendizagem. E essa ação demanda uma postura de comprometimento e abertura para as práticas de ensino que der significado a esse processo.

Nesse sentido, a busca de recursos didáticos que auxiliem o processo de ensino e a aprendizagem de conteúdos matemáticos é imprescindível nesse processo.

De certo modo, pode reconhecer que nem todo professor de matemática busca refletir sobre a prática docente, pois de acordo com Fiorentini e Miorim (1990) os professores de matemática nem sempre têm clareza dos motivos pelos quais os materiais ou jogos são importantes para o ensino e a aprendizagem da matemática, mas têm consciência da necessidade desses jogos na sala de aula e suas contribuições para o aluno aprender os conteúdos.

Logo,

$\mathrm{O}$ homem tem recorrido à ajuda de materiais concretos para o ajudar em atividades matemáticas desde os tempos mais longínquos. Por exemplo, o homem primitivo começou por usar marcas num bastão para fazer a contagem das ovelhas; usou pedras; usou a corda com nós; etc. Mais tarde, com a introdução do sistema de numeração indo-arábico, aparece o ábaco. Este foi um dos primeiros materiais construídos especificamente para trabalhar conceitos de aritmética.. Posteriormente aparecem na geometria a régua, o compasso e o esquadro. No séc. XVI existem gravuras onde se pode ver o uso destes instrumentos. VALE (2002, p. 9-10)

Portanto, o uso de materiais concretos não é recente, vem de uma necessidade do ser humano. O uso de tais ferramentas facilitou a resolução de seus problemas, pois, em sala de aula, pode vir a facilitar a aprendizagem dos estudantes, tendo em vista que ao manipular os materiais não vão apenas receber o conhecimento, vão participar ativamente da construção do conhecimento. 
Algumas reflexões sobre a História da Matemática e as contribuições da Torre de Hanói na aprendizagem de função exponencial

Raul Gomes Antunes, Lucas Ruan dos Santos Cardoso e João Batista Rodrigues da Silva

Para Costa Júnior; Silva; Lopes (2013), o professor deve se perguntar sobre o porquê da utilização de determinado material didático, a necessidade do uso, qual material irá usar, em qual momento. Sobretudo, ressaltam a reflexão do professor acerca do material a ser utilizado. Os respectivos autores mencionam também que o sucesso ou não da atividade está mais relacionado ao professor do que ao material, pois o material por si só não contém o conceito matemático.

Há pesquisas que indicam a eficácia do uso desses materiais manipulativos como ferramenta de auxílio no ensino de matemática. Como exemplo, a pesquisa de Botas e Moreira (2013) apresentam que o uso de materiais concretos e manipuláveis contribui para a aprendizagem dos estudantes, atuando como uma ferramenta motivadora. Ainda nessa pesquisa, as professoras abordam que os materiais didáticos são quaisquer materiais que auxiliem na aprendizagem dos estudos, sendo um elemento motivador, desempenhando um importante papel nas aulas de matemática e propiciando aos estudantes construírem seu próprio conhecimento a partir da interação com essas ferramentas. Esses professores afirmaram que os materiais são importantes, pois, para eles, são essenciais para o desenvolvimento de conceitos matemáticos.

De acordo com a literatura, há várias histórias que contam como teria surgido a Torre de Hanói, que é um jogo que consiste em uma plataforma com 3 hastes, 64 discos com diâmetros diferentes. O objetivo é passar os discos para uma haste usando outra como auxiliar. As regras são simples, os discos de maior diâmetro devem ficar sob os de menor diâmetro e, também, deve ser passado um de cada vez.

Lima (2013, p. 27) apresenta uma das histórias da Torre de Hanói:

O Jogo Torre de Hanói é também conhecida pelos nomes Quebra Cabeças do Fim do Mundo e Torre de Bramanismo, sendo divulgado pelo matemático francês Edouard Lucas no ano de 1883 [...], vendido como brinquedo. Sabe-se que o jogo era popular na China e no Japão e que veio do Vietnã. A inspiração do matemático se alicerça em uma lenda Hindu, que tratava de um templo em Benares, cidade de Santa da Índia, local que se encontrava uma torre sagrada do bramanismo, que tinha como função melhorar a disciplina mental de jovens monges. Conforme lenda, no grande templo de Benares, logo abaixo da cúpula que marca o centro do mundo, existia uma placa de bronze, que sobre a qual estariam fixadas três hastes de diamante. Em uma das hastes, o deus Brama, no momento da criação do mundo, colocou 64 discos de ouro puro, de modo que o disco maior permanecesse sobre a placa de bronze e os outros decrescendo até chegar ao topo. [...] acrescenta ainda que então os monges receberam a deliberação de transferir a torre formada pelos discos, de uma haste para outra, usando a terceira como auxiliar, com as restrições de movimentar um disco por vez e de jamais colocar um disco maior sobre um menor. Os respectivos monges deveriam manter a ação com eficiência noite e 
Algumas reflexões sobre a História da Matemática e as contribuições da Torre de Hanói na aprendizagem de função exponencial

Raul Gomes Antunes, Lucas Ruan dos Santos Cardoso e João Batista Rodrigues da Silva

dia e, quando terminassem o trabalho, o templo seria transformado em pó e assim o mundo sucumbiria e se acabava.

Vale apenas ressaltar que, embora existam várias versões da história da Torre de Hanói, elas convergem para um único ponto: ao passar todas as peças para a outra e haste o mundo se acabaria.

O estudante, ao conhecer essas histórias, pode pensar que é uma tarefa simples e que o mundo já teria acabado, por ter que apenas movimentar as peças ou, ainda, as histórias podem despertar, nos estudantes, a curiosidade, pelo fato de parecer, inicialmente, uma tarefa simples e, ao mesmo tempo, resultar - a partir das histórias contadas - numa catástrofe para o planeta. Por fim, pode perguntar o porquê desses movimentos a partir dos comandos. Por meio desse episódio o professor pode apresentar a relação existente entre a Torre de Hanói, com a lei de formação da função exponencial.

\section{Tecendo um caminho metodológico}

Frutos de discussão do grupo de pesquisa em Ensino de Ciências Naturais e Matemática, composto por professores e estudantes do Instituto Federal de Educação, Ciência e Tecnologia da Bahia, campus Juazeiro, sobre as dificuldades de aprendizagem em matemática dos estudantes do campus, surge a necessidade de promover atividades que visem mobilizar conhecimentos matemáticos envolvendo a História da Matemática e os materiais manipulativos.

Por meio de uma parceria realizada entre o IFBA, campus Juazeiro e a Universidade de Pernambuco ocorreu um dia de atividades envolvendo a matemática e algumas metodologias de ensino da matemática.

Este estudo se configura como qualitativo devido ser capaz de identificar e analisar os dados de acordo com a sua subjetividade. Assim, Godoy (1995) aborda que a pesquisa qualitativa não apresenta uma estrutura rígida, permite aos investigadores utilizar a criatividade propondo trabalhos com novas perspectivas.

A oficina foi planejada e ministrada pelos estudantes Andressa, Lucas Ruan, Raul, Ana Beatriz e o professor, João Batista.

No planejamento da oficina ocorreram vários debates a fim de definir uma estrutura que atendesse aos objetivos utilizando a ludicidade, interação e sintonia entre os membros promotores da oficina. Esta oficina aconteceu no Instituto Federal de Educação, 
Algumas reflexões sobre a História da Matemática e as contribuições da Torre de Hanói na aprendizagem de função exponencial

if "I iil Raul Gomes Antunes, Lucas Ruan dos Santos Cardoso e João Batista Rodrigues da Silva

Ciência e Tecnologia da Bahia - Campus Juazeiro, no dia 6 de maio de 2019, enaltecendo a matemática em comemoração da celebração de seu dia.

Com o título Reflexões sobre a História da Matemática e a Torre de Hanói na Aprendizagem da Função Exponencial, a oficina foi disponibilizada para 20 participantes, envolvendo estudantes da instituição sediadora do evento e estudantes de outras instituições de ensino do município de Juazeiro e de outros municípios.

Com duração de 04 horas, a oficina foi dividida em 06 momentos. No Primeiro momento, o objetivo era motivar o grupo para participar das atividades propostas. Então, os participantes foram recebidos pelos ministrantes com a dramatização da história da sopa de pedra. Essa encenação ocorreu com a contação da história de um viajante que tinha fome, mas sua vergonha não permitia que pedisse comida. Utilizou de estratégias para fazer comida e saciar a sua fome.

No segundo momento foram apresentadas algumas versões da história da Torre de Hanói, mostrando as várias lendas sobre o surgimento dessa Torre. Dentre elas uma das mais conhecidas que enfatiza que Brama (o primeiro deus da Trimúrti) havia criado uma suposta torre com 64 discos de ouro e mais duas estacas equilibradas sobre uma plataforma. Então ele ordenou que movimentassem todos os discos de uma estaca para outra, segundo as suas instruções.

Após o relato, foi distribuído entre todos os participantes um pequeno caçapalavras que continha algumas palavras relacionadas às histórias do surgimento da Torre de Hanói.

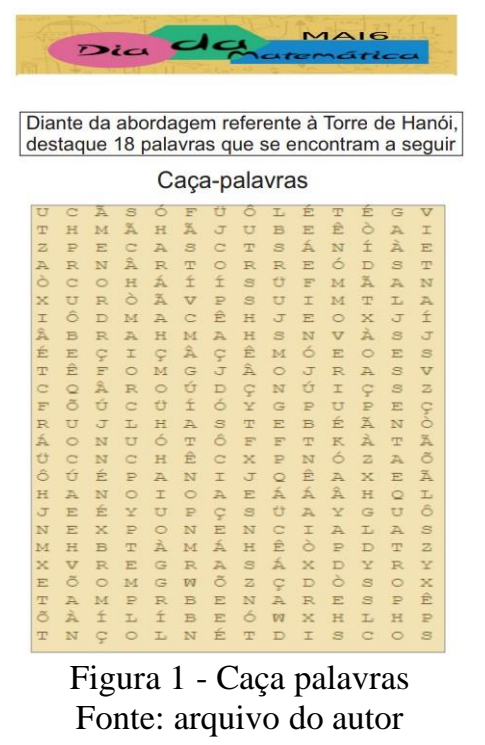


Algumas reflexões sobre a História da Matemática e as contribuições da Torre de Hanói na aprendizagem de função exponencial

Raul Gomes Antunes, Lucas Ruan dos Santos Cardoso e João Batista Rodrigues da Silva

Esta atividade contribuiu de forma dinâmica para que os participantes identificassem as palavras que foram discutidas no decorrer da história da Torre de Hanói.

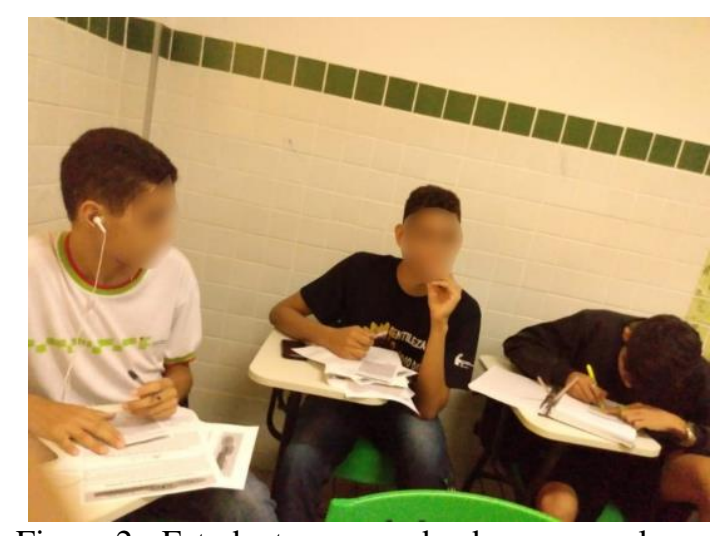

Figura 2 - Estudantes respondendo o caça-palavras Fonte: arquivo do autor

A maioria dos estudantes responderam em pouco tempo o caça-palavras, outros tiveram um pouco de dificuldade para encontrar as palavras e recapitular o contexto que estão inseridas.

No terceiro momento da oficina pedimos aos estudantes para tentarem relacionar a quantidade de peças e a também a quantidade de movimento que seriam dados. Após várias tentativas se estabeleceu a quantidade mínima de movimentos que teria que dar. Eles perceberam que ao aumentar a quantidade de peças aumentava consideravelmente a quantidade de movimentos a serem feitos. Fizeram as seguintes relações, como mostra a tabela a seguir:

Tabela 1 - Quantidade de movimentos na Torre de Hanói

\begin{tabular}{c|c}
\hline Quant. de peças & Quant. de movimentos \\
\hline $\mathbf{1}$ & 1 \\
\hline $\mathbf{2}$ & 3 \\
\hline $\mathbf{3}$ & 7 \\
\hline $\mathbf{4}$ & 15 \\
\hline \multicolumn{2}{|c}{ Fonte: Elaborada pelo autor }
\end{tabular}

Após o término dessa tarefa proposta foi iniciada uma sequência didática, por meio de uma resolução de problema, que relacionou os aspectos históricos da Torre de Hanói para o desenvolvimento das regras com a função exponencial. Foi indagado aos estudantes, sabendo que a quantidade mínima q de movimentos necessários, obedecendo as regras do jogo, é modelada pela expressão: $q=2^{\mathrm{n}}-1$, onde $\mathrm{q}$ é a quantidade mínima de movimentos e n é quantidade de peças utilizadas na torre, levando em consideração que 
Algumas reflexões sobre a História da Matemática e as contribuições da Torre de Hanói na aprendizagem de função exponencial

cada movimento levaria 1 segundo, quantos anos demoraria para acabar o mundo. Os estudantes tiverem um tempo de reflexão sobre essa atividade e, em seguida, fizemos um debate para saber se eles saberiam responder. Foi perceptível que tiveram dificuldade para achar o resultado, justificando que seria longo.

No quarto momento se iniciou uma discussão do conceito de função. Para isso, os participantes se reuniram em círculo e retiraram seus sapatos, para realizar uma brincadeira, cujo objetivo era relacionar as grandezas das funções com o tamanho dos pés e dos sapatos.

Os participantes gostaram do momento, pois a partir uma relação simples foi que eles conseguiram relacionar as grandezas das funções. Em seguida, iniciou uma discussão mais detalhada acerca da função exponencial.

No quinto momento foi distribuído novamente para os participantes outra atividade que foi utilizada para mobilizar os conhecimentos adquiridos durante a oficina. As questões se referiam à função exponencial e à Torre de Hanói.

Por fim, no último momento, ocorreu um campeonato com as Torres de Hanói. Ficou evidente a preocupação que os estudantes tinham para utilizar a quantidade mínima de movimentos. Conforme mostra a figura a seguir.

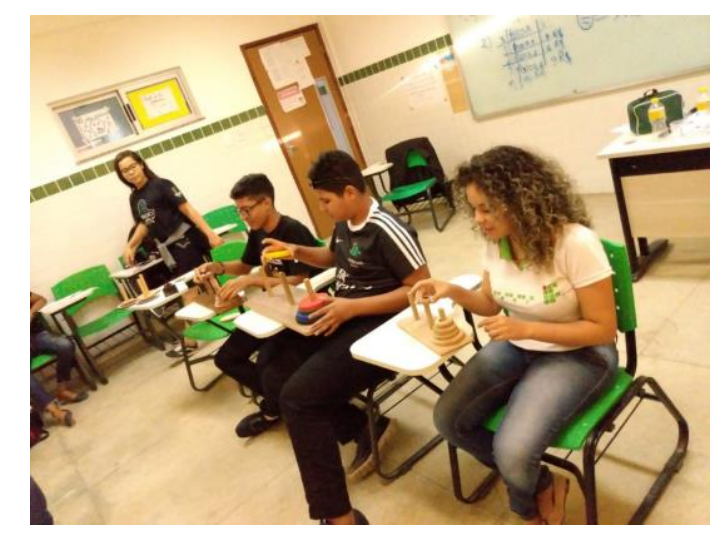

Figura 3 - Campeonato de Torres de Hanói

Fonte: imagem do autor

Percebe-se, ao finalizar a oficina, que os estudantes compreenderam que a matemática tem seu destaque histórico e se faz presente em jogos, materiais manipulativos, dentre outros. Vale destacar que o estudo da função exponencial ocorreu com mais significado. Por isso, Maslowski (2017) ressalta que o jogo é uma brincadeira 
Algumas reflexões sobre a História da Matemática e as contribuições da Torre de Hanói na aprendizagem de função exponencial

Raul Gomes Antunes, Lucas Ruan dos Santos Cardoso e João Batista Rodrigues da Silva

motivadora que desperta prazer em jogar e querer aprender, possibilitando construir um novo olhar sobre o conteúdo matemático.

\section{Conclusão}

A História da Matemática como metodologia de ensino teve fundamental importância na compreensão da função exponencial, por meio da Torre de Hanói. Lidar com essa ferramenta tem potencializado o ensino da matemática dando significado à aprendizagem. Conceber a História da Matemática de forma coerente ajuda a traçar um caminho metodológico que repercute na aprendizagem.

É notório, na descrição da vivência da oficina, o quanto as atividades envolvendo a história da matemática, jogos e uma sequência didática promoveram um ensino mais prazeroso, reflexivo, interativo e dinâmico.

\section{Referências}

BOTAS, Dilaila; MOREIRA, Darlinda. A utilização dos materiais didáticos nas aulas de Matemática: Um estudo no $1^{\circ}$ Ciclo. Revista Portuguesa de Educação. Portugal, v. 26, p. 254-278, mar./2013. Disponível em:

http://www.scielo.mec.pt/pdf/rpe/v26n1/v26n1a10.pdf. Acesso em: 27 jun. 2019.

COSTA, Alexandre da. Torre de Hanói, uma proposta de atividade para o ensino médio. Disponível em: <

http://www.pucrs.br/edipucrs/erematsul/comunicacoes/2ALEXANDREDACOSTA.pdf $>$ Acesso em: 18 jan. de 2020

COSTA JÚNIOR, J. R.; SILVA, J. B. R; LOPES, M. M. Uma breve análise das concepções acerca da utilização do laboratório de ensino de matemática na formação inicial. VI Congresso Internacional de Ensino de Matemática: Rio Grande do Sul, n. 6 p. 1-10, jun./2013. Disponível em:

http://www.conferencias.ulbra.br/index.php/ciem/vi/paper/viewFile/1192/563. Acesso em: 27 jun. 2019.

DIAS, M. S.; SAITO, F. Interface entre história da matemática e ensino: uma aproximação entre historiografia e perspectiva lógico-histórica. In: SEMINÁRIO INTERNACIONAL DE PESQUISA EM EDUCAÇÃO MATEMÁTICA, 4., 2009, Brasília. Anais... Brasília: SBEM, 2009. p. 1-14.

ENCONTRO REGIONAL DE ESTUDANTES DE MATEMÁTICA DA REGIÃO SUL FUNDAÇÃO UNIVERSIDADE FEDERAL DO PAMPA, 10., 2014, Bagé. A história da matemática e o processo de ensino aprendizagem. Bagé: Anais..., 2014. Disponível em: 
Algumas reflexões sobre a História da Matemática e as contribuições da Torre de Hanói na aprendizagem de função exponencial

Raul Gomes Antunes, Lucas Ruan dos Santos Cardoso e João Batista Rodrigues da Silva

<https://eventos.unipampa.edu.br/eremat/files/2014/12/PO_oliveira_00971876070.pdf>. Acesso em: 18 jan. 2020.

FIORENTINI, Dario; MIORIM, Maria Ângela. Uma reflexão sobre o uso de materiais concretos e jogos no Ensino da Matemática. Boletim SBEM-SP, São Paulo, v. 4, n. 7, p. 5-10, jul-ago, 1990

GODOY, Arilda Schmidt. Pesquisa qualitativa tipos fundamentais. Revista de Administração de Empresas, São Paulo, v. 35, n. 3, p.20-29, maio/jun 1995.

LARA, Isabel Cristina Machado de. O ensino da matemática por meio da história da matemática: possíveis articulações com a etnomatemática. Vidya, Santa Maria, v. 33, n. 2, p.51-62, jul/dez. 2013.

MASLOWSKI, Rogério José. O ensino da matemática através de jogos. CONGRESSO INTERNACIONAL DE EDUCAÇÃO CIENTÍFICA E TECNOLÓGICA. 2017, Santo Ângelo.

SILVA, M. J. D. C; SCARPA, Rosilene Cristina. O ensino da matemática e a utilização de materiais concretos para a sua aprendizagem. Campinas, p. 243-247, nov./2007. Disponível em:

https://repositorio.pgsskroton.com.br/bitstream/123456789/1314/1/Artigo\%2033.pdf. Acesso em: 27 jun. 2019.

VALE, Isabel; Materiais Manipuláveis. Edição. Viana do Castelo [s.n.], 2002. p. 1-54. COSTA JÚNIOR; formação inicial. VI Congresso Internacional de Ensino de Matemática: Rio Grande do Sul, n. 6 p. 1-10, jun./2013. Disponível em: http://www.conferencias.ulbra.br/index.php/ciem/vi/paper/viewFile/1192/563. Acesso em: 27 jun. 2019. 